\title{
Technical note: Common characteristics of directional spreading-steepness joint distribution in freak wave events
}

\author{
Shouhua Liu ${ }^{1}$, Yizhen $\mathrm{Li}^{2}$, and Xinyang Yue ${ }^{1}$ \\ ${ }^{1}$ National Marine Data and Information Service, Tianjin, China \\ ${ }^{2}$ Applied Ocean Physics and Engineering, Woods Hole Oceanographic Institution, Woods Hole, MA, USA \\ Correspondence to: Shouhua Liu (huazai950@hotmail.com) and Xinyang Yue (yue_xin_yang@outlook.com)
}

Received: 23 September 2015 - Published in Ocean Sci. Discuss.: 14 January 2016

Revised: 19 April 2016 - Accepted: 4 May 2016 - Published: 9 June 2016

\begin{abstract}
Seven freak wave incidents previously documented in the real ocean in combination with model hindcast simulations are used to study the variations associated with freak-wave-related parameters, such as wave steepness, directional spreading, and frequency bandwidth. Unlike the strong correlations between the freak wave parameters and freak waves' occurrence which were obtained in experimental and physical research, the correlations are not clear in the freak waves occurring in the real ocean. Wave directional spreading-steepness joint distribution is introduced and common visual features were found in the joint distribution when freak waves occur among seven "freakish" sea states. The visual features show that freak wave incidents occur when the steepness is large and directional spreading is small. Besides large steepness and small directional spreading, a longduration, relatively rough sea state is also necessary for the freak wave generation. The joint distribution is more informative than any single statistical wave parameter. The continuous sea states of local large steepness and small directional spreading are supposed to generate freak waves, and twodimensional distribution visualization is found to be a useful tool for freak waves' forecast. The common visual features of joint distributions supply an important cue for the theoretical and experimental research.
\end{abstract}

\section{Introduction}

Freak wave (also known as rogue wave, extreme wave, and unexpected wave) events have been a hot topic during the last decades in engineering and science research. Recently, two candidate mechanisms that lead to freak waves have been debated. One is linear and the other is nonlinear. The linear mechanism is considered to be a result of linear focusing in fixed time and position due to ocean waves' dispersion, geometrical, current, and wind force (Kharif and Pelinovsky, 2003). Nevertheless, freak waves are essentially a nonlinear phenomenon because of the large wave steepness of freak waves. Freak waves could also be produced as a result of the instability of ocean waves. Because of the abrupt and huge energy focusing characteristics of freak waves, the instability is considered to be self instability rather than externally forced. Benjamin and Feir (1967) found the instability of uniformly traveling trains of Stokes waves, the Benjamin-Feir instability (B-F instability). B-F instability is considered as the most probable candidate for the freak wave occurrence, which has been validated by lots of experimental and physical results. The studies on freak waves' dynamics are mostly focused on the B-F instability and extreme wave events can be caused by B-F instability in various circumstances.

From the engineering point of view, the experimental and theoretical achievements should be validated in the ocean and be applied in practice. Validation is difficult due to the rareness of freak waves and insufficient large-scale measurements. Most of the in situ observations of freak waves are time series surface elevation measurements, which can not provide spatial and directional spectrum information. There are some efforts that aim to set up a freak wave early-warning system in the ocean by experimental and theoretical research (Janssen, 2003; Mori and Janssen, 2006; Mori et al., 2011; Akhmediev et al., 2011a, b). Recent research found that some wave parameters have high correlation with freak waves' occurrence. Under unidirectional or small directional spreading (long-crested) conditions, the probability of freak waves 

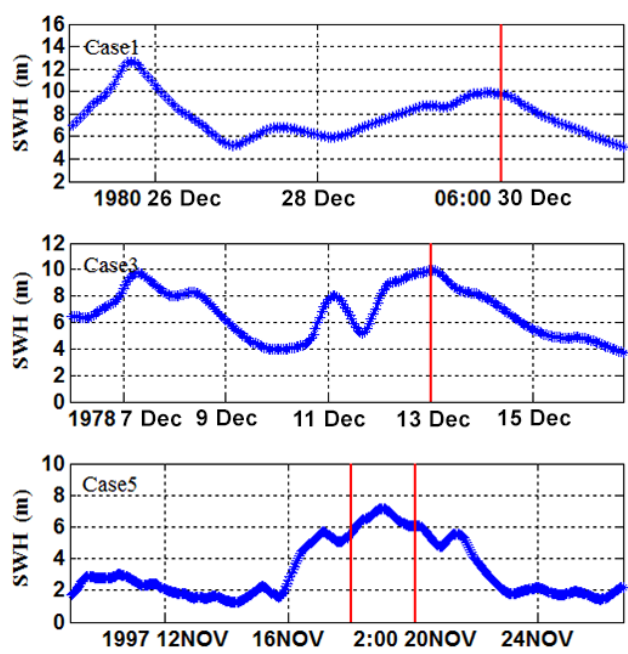
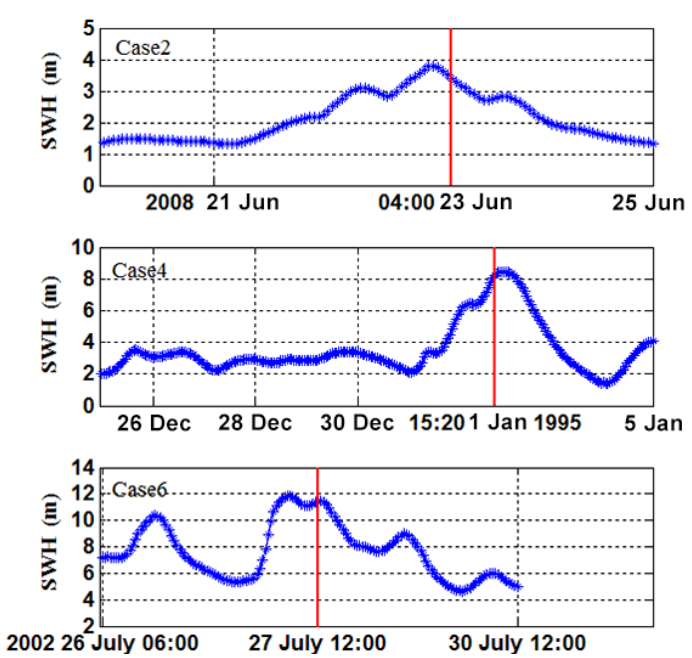

Figure 1. Time series of simulated significant wave height (cases 1-6), red lines refer to the freak waves occurrence time.

is considered to increase when wave steepness increases and spectrum narrows (Gramstad and Trulsen, 2007; Waseda et al., 2009; Onorato et al., 2010). According to the results of hindcast simulated "freakish" sea states, it is expected to find the conditions that trigger freak waves in the ocean and check if the theoretical and experimental findings are also applicable to oceanic freak waves. This check gives useful information of certain circumstances which trigger freak waves and complement existing theoretical framework of freak waves.

\section{Model configurations}

As a state-of-the-art, third-generation spectral model, WAVEWATCH III (WW3) (Tolman, 2002, 2009) offers good descriptions of statistical sea states from a kinetic approach that well mimics the directional spectrum. Although the WW3 model can not simulate freak waves, the freak-waverelated parameters deduced from simulated results can be considered as an approximation of corresponding parameters of statistical sea states which is pertinent to freak waves. Short-lived freak waves can last only for a few wave periods (Janssen, 2003) and hardly influence relatively long-time wave statistical characteristics (Toffoli and Bitner-Gregersen, 2011). Even in complex conditions, evolution of the spectrum within the kinetic description appears to be consistent both qualitatively and quantitatively with solutions for the weakly nonlinear dynamical equations for ocean waves (Zakharov et al., 2007; Badulin et al., 2008).

Seven freak wave incidents in the ocean used in this study and the defined model grid are shown in Table 1. Hindcast simulations are conducted by WW3 multigrid technique. The simulated results are easily affected by the errors propagated from the outside boundary of model grid, so the inner grids that cover the freak wave incidents' positions are set in the middle of outer grids. The coarse resolution for outer grid is $0.25^{\circ} \times 0.25^{\circ}$ and the fine resolution for the inner is $0.1^{\circ} \times 0.1^{\circ}$. The implementations of WW3 in our simulations use the default model setting as defined in Tolman $(2002,2009)$ with few exceptions. The wave directions are resolved to $10^{\circ}$ (36 "bins") and frequencies ranges from 0.0412 to 0.4056 in 25 bands, with the increment factor of 1.1. The freak wave incidents do not occur in the shallow water, so only three source terms are considered in the model: wind-wave interaction term, nonlinear wave-wave interactions term, and a dissipation (whitecapping) term. We force the wave model using the Cross-Calibrated Multi-Platform Ocean Surface Wind Velocity (Atlas et al., 2011), which has $0.25^{\circ}$ resolution at $6 \mathrm{~h}$ intervals. A reanalysis ocean current from National Marine Data \& Information Service (China) is also taken into account in the model for the diagnosis of the results. The nonlinear wave-wave interaction term is calculated by the high-resolution DIA method (Tolman, 2002). WW3 always needs 1-2 days to spin up in "cold start" conditions. In our simulations, we allow more than 3 days for the model to spin up before the freak wave incident time.

\section{Results and discussion}

Seven hindcast simulations are aimed to obtain the directional spectrum that covers the time span for the freak waves. Statistical wave parameters, including significant wave height $\left(H_{\mathrm{s}}\right)$, wave steepness $(\delta)$, directional spreading $\left(\sigma_{\theta}\right)$, frequency peakedness $\left(Q_{\mathrm{p}}\right)$, and $\mathrm{BFI}$ (the ratio between steepness and spectral bandwidth) are derived from directional spectrum. The $H_{\mathrm{s}}, \delta$, and $\sigma_{\theta}$ are defined following Tolman (2002). $Q_{\mathrm{p}}$ and BFI (Eqs. 1 and 2) are defined following Janssen and Bidlot (2003). We seek to check the parameters that have a close relationship with freak wave occurrence and find physically meaningful factors common to "freakish" sea 

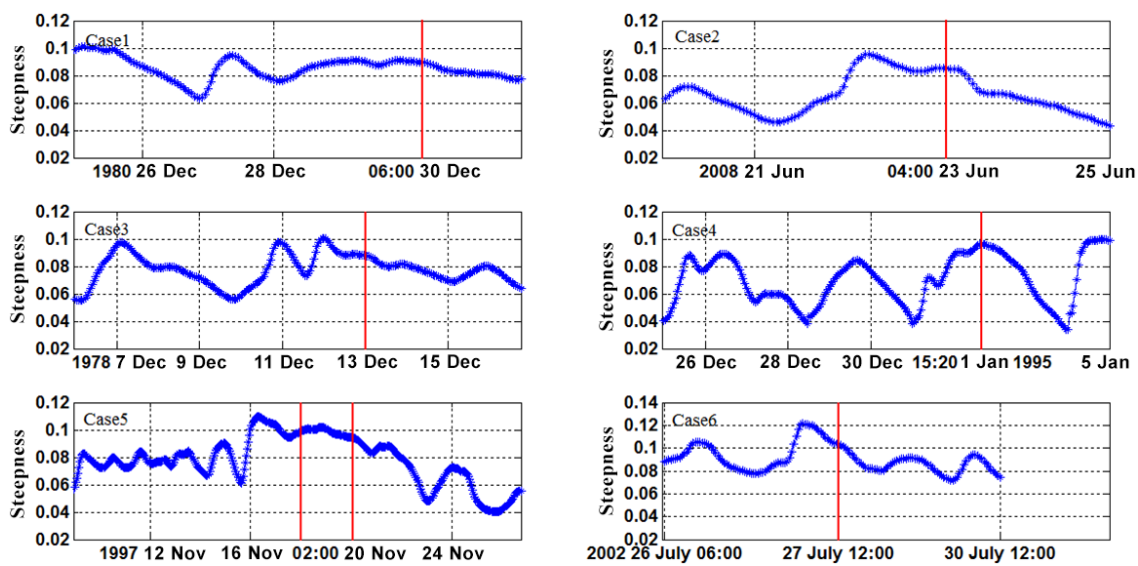

Figure 2. Time series of simulated wave steepness (cases 1-6), red lines refer to the freak waves occurrence time.
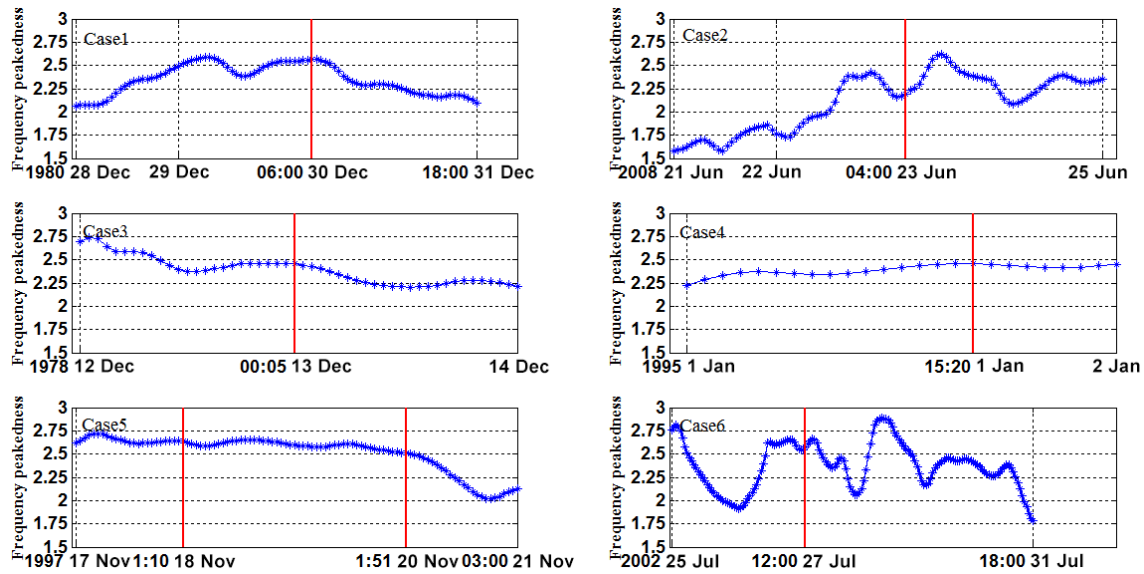

Figure 3. Time series of simulated frequency peakedness (cases 1-6), red lines refer to the freak waves occurrence time.

states.

$Q_{\mathrm{p}}=2 m_{\mathrm{o}}^{-2} \int_{0}^{\infty} \sigma\left[\int_{0}^{2 \pi} F(\sigma, \theta) \mathrm{d} \theta\right]^{2} \mathrm{~d} \sigma$

$\mathrm{BFI}=k_{\mathrm{o}} m_{\mathrm{o}}^{1 / 2} Q_{\mathrm{p}} \sqrt{2 \pi}$,

where $\sigma$ is the relative radian frequency, $\theta$ is the wave direction, $k_{\mathrm{o}}$ is the wave number, $F$ is the wave energy density spectrum, and $m_{\mathrm{o}}$ is the zero order moment of $F$.

$H_{\mathrm{S}}$ is an important parameter that characterizes the mean sea states. It always takes a local extreme value (cases 1, 3 , and 6) or near-extreme value when freak waves occur (Fig. 1). Many in situ observations have demonstrated that the freak wave occurrence will increase significantly in quite rough seas (Guedes et al., 2003; Liu et al., 2009), so the quasi-local extreme value feature is self consistent to some extent. Case 5 indicates that freak wave events may occur when the $H_{\mathrm{s}}$ values are not the highest locally in continuous time series, unlike the other cases' quasi-local extreme value feature (Fig. 1, case 5). This means freak waves can also take place relatively far away from local extreme sea states.

Steepness, spectral bandwidth, and directional spreading are fundamental wave indices for freak wave occurrence. BFI has been considered as a good freak wave occurrence indicator (Janssen, 2003), yet it does not work very well for directional ocean waves (Gramstad and Trulsen, 2007; Onorato et al., 2010). Steepness in cases 1-6 when freak waves happen is always above 0.08 , which is a relatively large value for ocean waves' statistical characteristics (Fig. 2). Spectral bandwidth is parameterized by frequency peakedness. The temporal change of frequency peakedness (Fig. 3) is often time similar to that of BFI (Fig. 4) on account of the direct proportion relation between them according to Eq. (2), as in cases $1,4,5$, and 6 . BFIs at freak wave occurrence time are too small to be consistent with experimental and physical conclusions; BFI is supposed to be larger than 1 when freak waves occur (Janssen, 2003). Similar results are also found by Bertotti and Cavaleri (2008) and Burgers et al. (2008). Freak waves are influenced significantly by the directionality 
Table 1. Time, position information, and model setup of freak wave incidents.

\begin{tabular}{llllll}
\hline Case & Time (UTC) & Position & $\begin{array}{l}\text { Outer grid } \\
\text { of model }\end{array}$ & $\begin{array}{l}\text { Inner grid } \\
\text { of model }\end{array}$ & Note \\
\hline Case 1 & 30 Dec 1980 05:30 & $\begin{array}{l}156^{\circ} 11^{\prime} \mathrm{E}, \\
31^{\circ} \mathrm{N}\end{array}$ & $\begin{array}{l}115-180^{\circ} \mathrm{E}, \\
10-65^{\circ} \mathrm{N}\end{array}$ & $\begin{array}{l}140-160^{\circ} \mathrm{E}, \\
25-40^{\circ} \mathrm{N}\end{array}$ & $\begin{array}{l}\text { Northwest } \\
\text { Pacific }\end{array}$ \\
\hline Case 2 & 23 Jun 2008 04:00 & $\begin{array}{l}144-145^{\circ} \mathrm{E}, \\
35-36^{\circ} \mathrm{N}\end{array}$ & $\begin{array}{l}115-180^{\circ} \mathrm{E}, \\
10-65^{\circ} \mathrm{N}\end{array}$ & $\begin{array}{l}140-160^{\circ} \mathrm{E}, \\
25-40^{\circ} \mathrm{N}\end{array}$ & $\begin{array}{l}\text { Northwest } \\
\text { Pacific }\end{array}$ \\
\hline Case 3 & 13 Dec 1978 00:00 & $\begin{array}{l}44^{\circ} \mathrm{N}, \\
24^{\circ} \mathrm{E}\end{array}$ & $\begin{array}{l}70^{\circ} \mathrm{W}-10^{\circ} \mathrm{E}, \\
10-75^{\circ} \mathrm{N}\end{array}$ & $\begin{array}{l}30-20^{\circ} \mathrm{W}, \\
40-50^{\circ} \mathrm{N}\end{array}$ & Atlantic \\
\hline Case 4 & 1 Jan 1995 15:20 & $2^{\circ} 28^{\prime} \mathrm{E}$, & $70^{\circ} \mathrm{W}-10^{\circ} \mathrm{E}$, & $5^{\circ} \mathrm{W}-5^{\circ} \mathrm{E}$, & New year \\
& & $58^{\circ} 11^{\prime} \mathrm{N}$ & $10-75^{\circ} \mathrm{N}$ & $55-65^{\circ} \mathrm{N}$ & wave \\
\hline Case 5.1 & 18 Nov 1997 01:10 & $1^{\circ} 44^{\prime} \mathrm{E}$, & $70^{\circ} \mathrm{W}-10^{\circ} \mathrm{E}$, & $5^{\circ} \mathrm{W}-5^{\circ} \mathrm{E}$, & Alwyn oil \\
\cline { 1 - 4 } Case 5.2 & 20 Nov 1997 01:51 & $60^{\circ} 45^{\prime} \mathrm{N}$ & $10-75^{\circ} \mathrm{N}$ & $55-65^{\circ} \mathrm{N}$ & platform \\
\hline Case 6 & 27 Jul 2002 12:00 & $\begin{array}{l}22.17^{\circ} \mathrm{E}, \\
37.97^{\circ} \mathrm{S}\end{array}$ & $\begin{array}{l}0.5-60^{\circ} \mathrm{E}, \\
70^{\circ} \mathrm{S}-0^{\circ} \mathrm{N}\end{array}$ & $\begin{array}{l}17-27^{\circ} \mathrm{E}, \\
43-33^{\circ} \mathrm{S}\end{array}$ & $\begin{array}{l}\text { FA } \\
\text { platform }\end{array}$ \\
\hline
\end{tabular}

Cases 1, 2, and 3 are for ship sinkings which are thought to be caused by freak waves. Cases 4, 5, and 6 are freak waves that are recorded by in situ measurements.
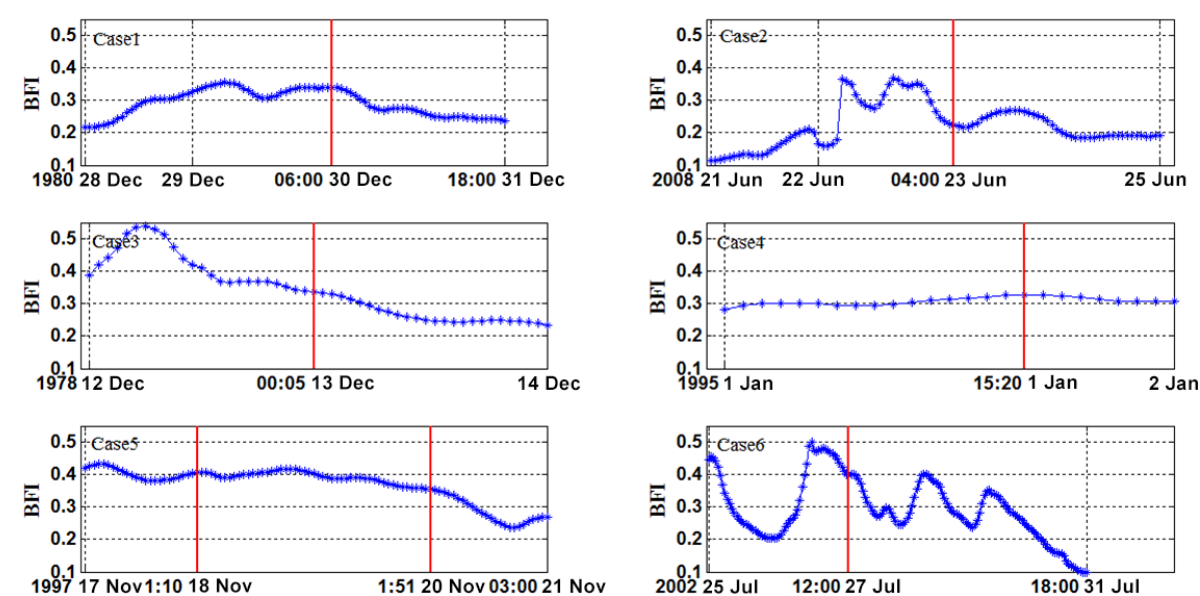

Figure 4. Time series of simulated BFIs (cases 1-6), red lines refer to the freak waves occurrence time.

of ocean waves and it is almost impossible to generate freak waves in large directional spreading. Hence, the directionality of ocean waves is thought to be responsible for the inconsistency of BFI values. The directional spreading values among cases $1-6$ are relatively small: less than $25^{\circ}$, except case $2\left(37.3^{\circ}\right)$ (Fig. 5). It also demonstrates that the freak waves are not clearly related to any wave parameter's absolute value. In contrast, the freak waves should be more associated with the wave parameter's value relative to before and after a period of time.

In summary, there are no obvious relationships between single wave parameters and freak wave incidents. Freak wave are considered to result from B-F instability, so should be triggered under multiple conditions rather than one and it is not easy to find any clues from single wave parameters.
Joint distributions of wave parameters that are in close relation with freak wave occurrence are more reasonable representation. Tamura et al. (2009) and In et al. (2009) have introduced frequency peakedness-directional spreading joint distribution to explore the freak wave occurrence circumstance. The joint distributions of two freak wave samples that they used in their research show similar visual features. We find that there are always some abrupt changes in frequency peakedness when the spectrum changes from single peak to double peak. For this reason, the frequency peakedness is not used in the joint distributions. Freak waves are strong nonlinear phenomena, whose occurrences are closely related to ocean waves' directionality. With a consideration of nonlinearity and directionality of ocean waves, wave directional 

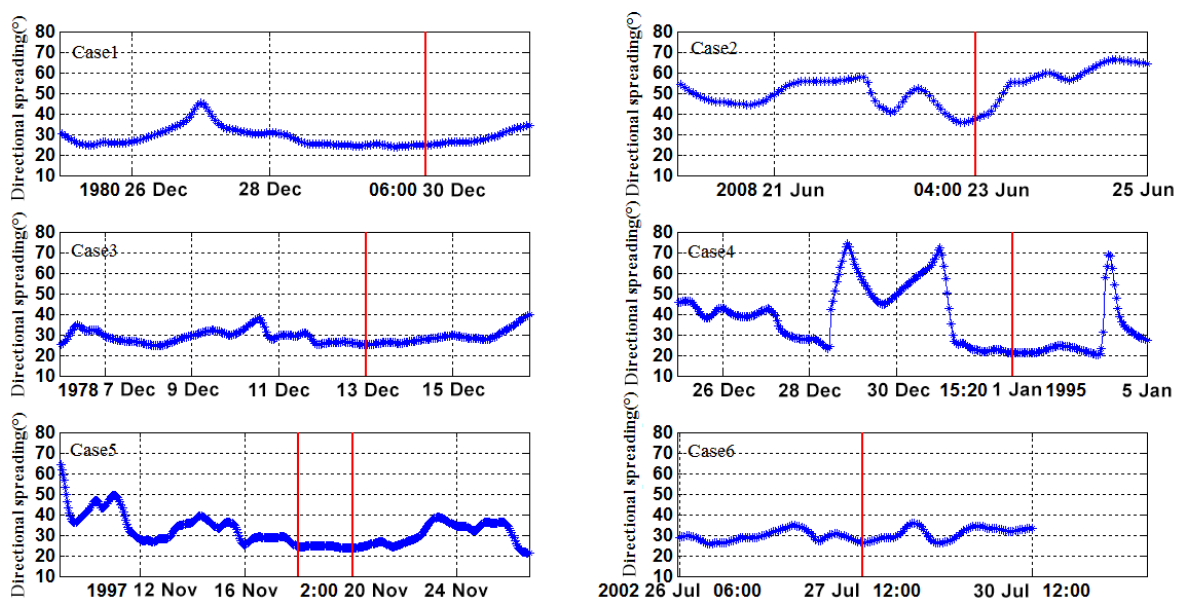

Figure 5. Time series of simulated directional spreading (cases 1-6), red lines refer to the freak waves occurrence time.
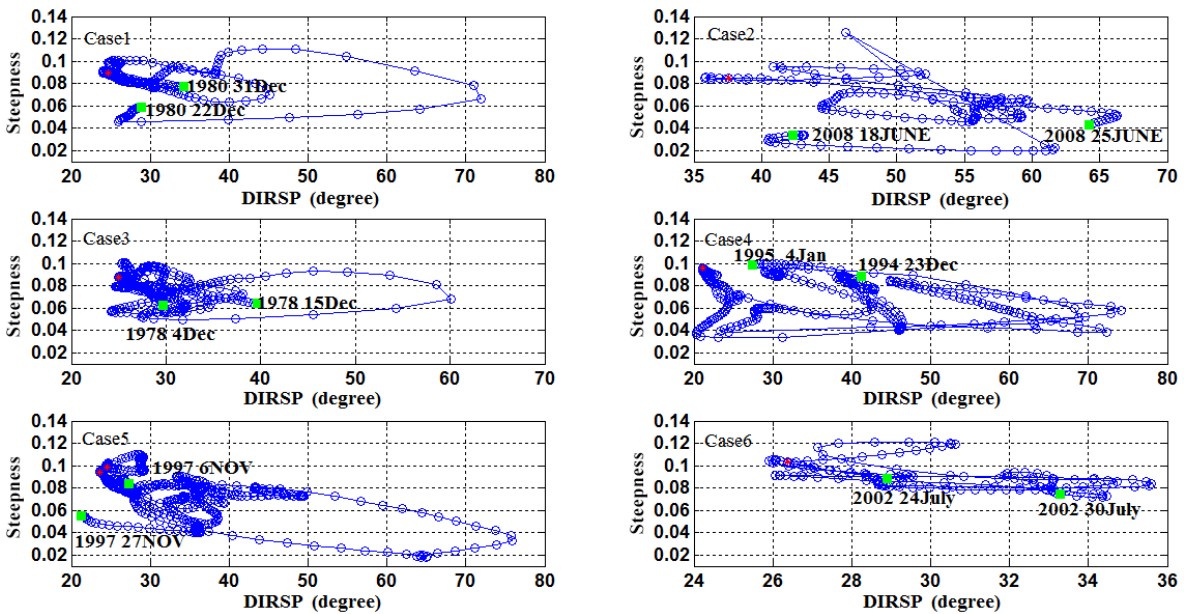

Figure 6. Joint scatter plot of directional spreading and steepness by $1 \mathrm{~h}$ during 7-20 days around the freak waves' occurrence time (cases $1-$ 6); red stars refer to the freak wave occurrence time, green rectangles refer to the start and end time.

spreading-steepness joint distribution is used to analyze the freak wave incidents in this research.

An obvious visual common feature is shown in six wave directional spreading-steepness joint distributions (Fig. 6). Although it is not obvious in any single parameter, the joint distributions show large steepness and small directional spreading characteristics at freak waves' time. This is quantitatively consistent with experimental and theoretical research conclusions (Gramstad and Trulsen, 2007; Waseda et al., 2009; Onorato et al., 2010). Second, the points are intensive around freak waves' time. It means that large steepness and small directional spreading are continuous over a long period of time. New information given in two characteristics implies a certain circumstance that is suitable for triggering freak waves. A continuous sea state with large steepness $(>0.08)$ and small directional spreading $\left(<27^{\circ}\right)$ lasting a long time means a "freakish" sea state. Third, the freak wave occurrence time is always near or at the extreme point of joint distribution. It demonstrates the freak wave sea states are near or at the maximum of wave steepness or minimum of directional spreading.

Case 2 was moderate sea state; the steepness was 0.082 and the directional spreading was $37.3^{\circ}$ when the suspected freak wave occurred. The directional spreading in case 2 is too broad to trigger freak waves according to experimental and numerical research results. However, it is relatively small during 7-day period (Fig. 6, case 2). The freak wave occurrence point is also on the upper left corner of Fig. 6, which is similar to distribution in other cases. Hence, it is thought that freak waves are dependent more on relative sea states rather than absolute sea states. Some freak wave incidents also occurred in rather low sea states with the scenario of rapidly changing conditions or crossing seas (Toffoli et al., 2004). Joint distribution in case 2 (Fig. 6) shows a rapid change in direction spreading, which may be responsible for the suspected freak waves. The obvious visual commonal- 
ity of the joint distribution shows local extreme conditions and rapid changes of sea state parameters. It always signifies a considerable increase of freak wave occurrence as wave steepness increases and directional spreading narrows. In addition, a long duration of this combination may be necessary for "freakish" sea states; how long it should be is not clear from the present evidence and awaits future study.

\section{Conclusions}

Experimental and theoretical approaches both suggest that the freak waves are triggered under small directional spreading, large steepness, and narrow spectrum bandwidth conditions. The attempt to characterize freak wave sea states from single wave parameters is likely impossible. The characteristics with regard to variability of steepness and directional spreading are shown by joint distributions. There are regions that always mean "freakish" seas, which are situated on the upper left corner of the joint distribution figure. In long duration joint distribution of directional spreading-steepness, "freakish" sea states have a visual common feature that steepness is large, directional spreading is relatively narrow, and the state lasts a long time.

Multidimensional evolution of wave parameters contains more information, so it is better suited for analysis. The visual commonality here suggests a tool to characterize freak wave sea states and can be validated by long time series observation in the future.

Acknowledgements. We thank the reviewers for their valuable comments. We are grateful to the Physical Oceanography Distributed Active Archive Center (PO.DAAC) at the NASA Jet Propulsion Laboratory (JPL) for the CCMP wind. This work is supported by the National Natural Science Foundation of China (Grant no. 41406032).

Edited by: J. M. Huthnance

\section{References}

Akhmediev, N., Ankiewicz, A., Soto-Crespo, J. M., and Dudley, J. M.: Rogue wave early warning through spectral measurements?, Phys. Lett. A, 375, 541-544, 2011a.

Akhmediev, N., Soto-Crespo, J. M., Ankiewicz, A., and Devine, N.: Early detection of rogue waves in a chaotic wave field, Phys. Lett. A, 375, 2999-3001, 2011b.

Atlas, R., R. N. Hoffman, J. Ardizzone, S. M. Leidner, J. C. Jusem, D. K. Smith, and Gombos, D.: A cross-calibrated, multiplatform ocean surface wind velocity product for meteorological and oceanographic applications, B. Am. Meteorol. Soc., 92, 157174, 2011.

Badulin, S. I., Korotkevich, A. O., Resio, D., and Zakharov, V. E.: Wave-wave interactions in wind-driven mixed seas, in: The Proceedings of Rogue Waves 2008, Brest, France, 13-18 October 2008, 77-86, 2008.
Benjamin, T. B. and Feir, J. E.: The disintegration of wavetrains on deep water, Part 1: Theory, J. Fluid Mech., 27, 417-430, 1967.

Bertotti, L. and Cavaleri, L.: Analysis of the Voyager storm, Ocean Eng., 35, 1-5, 2008.

Burgers, G., Koek, F., Hans, D. V., and Stam, M.: Searching for factors that limit observed extreme maximum wave height distributions in the North Sea, in: Extreme Ocean Waves, 127-138, 2008.

Gramstad, O. and Trulsen, K.: Influence of crest and group length on the occurrence of freak waves, J. Fluid Mech., 582, 463-472, 2007.

Guedes, S. C., Cherneva, Z., and Antão, E. M.: Characteristics of abnormal waves in North Sea storm sea states, Appl. Ocean Res., 25, 337-344, 2003.

In, K., Waseda, T., Kiyomastu, K., Tamura, H., Miyazawa, Y., and Iyama, K.: Analysis of a Marine accident and freak wave predition with an operational wave model, in: Proceedings of the Nineteenth (2009) International Offshore and Polar Engineering Conference, Osaka, Japan, 21-26 June 2009, 877-883, 2009.

Janssen, P. A. E. M.: Nonlinear four-wave interactions and freak waves, J. Phys. Oceanogr., 33, 863-884, 2003.

Janssen, P. A. E. M. and Bidlot, J.: New wave parameters to characterize freak wave conditions, Research Dept. Memo. R60.9.PJ/0387, ECMWF, Reading, UK, 2003.

Kharif, C. and Pelinovsky, E.: Physical mechanisms of the rogue wave phenomenon, Eur. J. Mech. B-Fluid., 22, 603-634, 2003.

Liu, P. C., Chen, H. S., Doong, D.-J., Kao, C. C., and Hsu, Y.-J. G.: Freaque waves during Typhoon Krosa, Ann. Geophys., 27, 2633-2642, 2009.

Mori, N. and Janssen, P. A. E. M.: On kurtosis and occurrence probability of freak waves, J. Phys. Oceanogr., 36, 1471-1483, 2006.

Mori, N., Onorato, M., and Janssen, P. A. E. M.: On the estimation of the kurtosis in directional sea states for freak wave forecasting, J. Phys. Oceanogr., 41, 1484-1497, 2011.

Onorato, M., Proment, D., and Toffoli, A.: Freak waves in crossing seas, Eur. Phys. J.-Spec. Top., 185, 45-55, 2010.

Tamura, H., Waseda, T., and Miyazawa, Y.: Freakish sea state and swell-windsea coupling: numerical study of the Suwa-Maru incident, Geophys. Res. Lett., 36, L01607, doi:10.1029/2008GL036280, 2009.

Toffoli, A. and Bitner-Gregersen, E. M.: Extreme and rogue waves in directional wave fields, The Open Ocean Engin. J., 4, 24-33, 2011.

Toffoli, A., Lefevre, J. M., Monbaliu, J., and Bitner-Gregersen, E.: Dangerous sea-states for marine operations, in: Proc. 14th Int. Offshore and Polar Eng. Conf. ISOPE, Toulon, France, 2004, 85$92,2004$.

Tolman, H. L.: User manual and system documentation of WAVEWATCH-III version 2.22, NOAA/NWS/NCEP/MMAB Tech Note 222, 139 pp., 2002.

Tolman, H. L.: User manual and system documentation of WAVEWATCH III version 3.14, NOAA/NWS/NCEP/MMAB Technical Note 276, 194 pp., 2009.

Waseda, T., Kinoshita, T., and Tamura, H.: Evolution of a random directional wave and freak wave occurrence, J. Phys. Oceanogr., 39, 621-639, 2009.

Zakharov, V. E., Korotkevich, A. O., Pushkarev, A., and Resio, D.: Coexistence of weak and strong wave turbulence in a swell propagation, Phys. Rev. Lett., 99, 1-5, 2007. 